\title{
Sporadic infantile bilateral striatal necrosis
}

INSERM

\section{Source}

INSERM. (1999). Orphanet: an online rare disease and orphan drug data base. Sporadic infantile bilateral striatal necrosis. ORPHA:225147

Sporadic infantile bilateral necrosis is the sporadic form of infantile bilateral striatal necrosis (IBSN; see this term), a syndrome of bilateral symmetric spongy degeneration of the caudate nucleaus, putamen and globus pallidus characterized by developmental regression, choreoathetosis and dystonia progressing to spastic quadriparesis. 